\title{
22 Sex in the city
}

\section{Maki Hirayama}

Sports mega-events have tended to be opportunities for an increase in sex work. Tokyo 2020 will also see a significant number of tourists looking for sexual services. Yet in contrast to what had been on offer in previous Olympic host cities, they may be in for a surprise. Japan's Anti-Prostitution Act of 1957 bans prostitution, defined as "vaginal intercourse," thus sexual services generally offer a range of options that include "anything but," such as fantasy-cosplay or erotic massages. And even in Tokyo's most famous red-light district Kabukicho, tourists will not find many flashy advertisements for erotic services since a clean-up campaign has pushed them into the backstreets. Instead, new services aided by the development of the Internet such as deriheru ("delivery health"), in which women are delivered to customers' locations, have increased dramatically since the 2000s. This system is criticized for women being more likely to be put in danger than in salons, where staff can guard them, and it creates difficulties in surveilling and controlling the activities of foreign sex workers and traffickers. However, it is expected that most Japanese sexual commerce agencies will not seek earnings from foreign tourists even during Tokyo 2020, because these tourists would likely expect intercourse and thus cause "problems."

Ironically, the expansion of Internet-based sexual services has negatively impacted Japan's "love hotel" business, and here foreign tourists may actually provide the key to their revival. Love hotels offer rooms to be rented usually on an hourly basis for couples to have sex and have recently attracted interest from tourists. The unusual appearance of love hotels ranges from outdoor design like castles to often very kitschy interior designs of windowless rooms with extravagant themes. Many of the love hotels were built in the 1970s, which suggests a liberated playfulness in Japanese sexuality during this period. However, in recent times love hotels have suffered from declining patronage from their conventional clientele due to changes in the sex industry like deriheru, which have caused them to become hotspots for sex workers and less attractive to average couples. In response, some hotels have actively welcomed foreign tourists, even introducing reservation systems connected to major online sites such as booking.com and employing Englishspeaking staff. During the 2020 Games, the capacity of general hotels will not be sufficient, so love hotels are expected fill the niche, possibly creating another evolution in this business. 